2. White EW, Weber JN, Roy DM, Owen EL. Replamineform porous biomaterials for hard tissue implant applications. J Biomed Mat Res Symp 1975;6:23-7.

3. Tanner KE, Downes RN, Bonfield W. Clinical applications of hydroxyapatite reinforced materials. Br Ceram Trans 1994;93:104-6.

4. Jonck LM, Grobbelaar CJ. A glass ionomer for reconstructive surgery. Ionogran: an ionomeric micro implant. A biological evaluation. J Clin Mat 1992;9:85-103.

5. Perry AC. Integrated orbital implants. Adv Ophthalmic Plast Reconstr Surg 1988;8:75-81.

6. Shields CL, Shields JA, Eagle RC Jr, De Potter P. Histopathologic evidence of fibrovascular ingrowth four weeks after placement of the hydroxyapatite orbital implant. Am J Ophthalmol 1991;111:363-6.

7. Shields CL, Shields JA, De Potter P. Hydroxyapatite orbital implant after enucleation: experience with initial 100 consecutive cases. Arch Ophthalmol 1992;110:333-8.

8. Rubin PAD, Popham JK, Bilyk JR, Shore JW. Comparison of fibrovascular ingrowth into hydroxya- patite and porous polyethylene orbital implants. Ophthalmic Plast Reconstr Surg 1994;10:96-103.

9. Buettner H, Bartley GB. Tissue breakdown and exposure associated with orbital hydroxyapatite implants. Am J Ophthalmol 1992;113:669-73.

10. Goldberg RA, Holds JB, Ebrahimpour J. Exposed hydroxyapatite orbital implants: report of six cases. Ophthalmology 1992;99:831-6.

11. Shields CL, Shields JA, De Potter P, Singh AD. Problems with the hydroxyapatite orbital implant: experience with 250 consecutive cases. $\mathrm{Br} \mathrm{J}$ Ophthalmol 1994;78:702-6.

12. Heidi D, Remulla MD, Peter AD, Rubin MD, John W, Shore MD, Francis C, Sutula MD, Daniel J, Townsend MD, John J, Woog MD, Kurt V, Jahrling BCO. Complications of porous spherical orbital implants. Ophthalmology 1995;102:586-93.

13. Ashworth JL, Rhatigan M, Sampath R, Brammar R, Sunderland S, Leatherbarrow B. The hydroxyapatite orbital implant: a prospective study. Eye 1996; 10:29-37.

\title{
ACUTE SYMPTOMATIC TOXOPLASMA RETINOCHOROIDITIS
}

The clinical diagnosis of acute toxoplasma retinochoroiditis is made on the characteristic features of intraocular inflammation with a focal retinitis adjacent to an old chorioretinal scar. There has been heightened professional and public awareness of congenital toxoplasmosis recently, particularly with respect to the value of screening (and treating) antenatal disease. ${ }^{1}$ However, it is apparent that little is known about the impact of this infection on longterm visual morbidity, less on the most appropriate methods of laboratory diagnosis and management and practically nothing on the way in which the parasite enters and encysts in retinal tissue or how it recurs many years later to produce symptomatic disease.

Epidemiological data derived from clinic-based follow-up studies have suggested that retinochoroidal lesions occur in over $80 \%$ of people with congenital toxoplasmosis. ${ }^{2,3}$ The proportion of affected people who eventually develop symptoms is not known. A recent study has, however, shown that the incidence of symptomatic disease in Britain might be much lower than that expected from the predicted prevalence of retinochoroidal lesions. ${ }^{4}$ This study showed an incidence of symptomatic disease in the native-born population of $0.4 / 100000$ per year. Therefore, assuming that each patient suffers a mean of two symptomatic attacks per lifetime, 100 people born in Britain may be affected each year about one-fifth of the estimated 500-600 people born with congenital disease. ${ }^{1}$ Interestingly, toxoplasma retinochoroiditis was almost 100 times commoner in patients born in West Africa. Since this was not a follow-up study the long-term impact on visual morbidity was not specifically addressed, although it was noted that vision transiently fell to $6 / 12$ or less in two-thirds of patients. The findings suggested that prenatal screening for toxoplasmosis in Britain to prevent visual loss might be of limited benefit.

It is becoming increasingly recognised that some acute symptomatic toxoplasma retinochoroiditis may be the result of acquired rather than congenital infection. In the absence of clinical or serological indicators of recent infection such cases are indistinguishable from congenital disease. Toxoplasma retinochoroiditis has been reported in siblings in Brazil and $20 \%$ of adults in this population had toxoplasma chorioretinal scars despite an incidence of a positive IgM against the organism in cord blood of $1 \% .^{5}$ Acquired disease is also reported to occur in immunocompromised patients but is much less common than toxoplasma encephalitis in this group. ${ }^{6}$ Confirmation of the diagnosis in all patients by laboratory testing is difficult given the high seroprevalence of antibodies to the parasite in most populations. Whilst IgM positivity has been taken to imply a recently acquired infection, current techniques are so sensitive that a positive result may last for 18 months after initial infection and IgM positivity has also been reported in recurrent disease. ${ }^{7}$ Newer techniques which involve the detection of parasite DNA in ocular fluid by the polymerase chain reaction are promising, but require further refinement.

There is no one drug regime that will eliminate 
toxoplasma from the human retina. Many combinations of antitoxoplasma agents (pyrimethamine, sulphonamides, clindamycin, trimethoprim or spiramycin) with systemic corticosteroids have been evaluated. No particular regimen seems to alter the natural course of acute symptomatic recurrent disease, to prevent recurrence itself, and all have potentially serious toxic side effects. ${ }^{8}$ This lack of therapeutic efficacy is reflected in the diversity of regimes used by ophthalmologists who treat this disease. ${ }^{9}$ Absolute indications for treatment are the presence of retinitis close to the optic disc or fovea and disease in immunocompromised patients. However, even in these circumstances, the failure to prevent recurrent disease often means that long-term visual loss may simply be delayed. Recent advances using atovaquone, a drug effective against both the active and encysted form of the parasite, show great promise and this may well become the first-line treatment of the future. ${ }^{10}$

Finally, more work is required on the pathogenesis of this infection. How does an organism carried intracellularly in the blood stream cross the bloodretinal barrier? Why does it encyst in the inner retinal layers and which particular retinal cells are more prone to infection than others? What factors in the host-parasite relationship are important in retinal damage, the long latency of recurrence of disease, and its reactivation? We do not know if some strains of the organism are more virulent than others nor whether differences in virulence might underlie the different epidemiological rates of infection in different countries. These questions and many others need to be answered to prevent and treat the commonest cause of posterior uveitis in the world with its attendant visual loss.

\section{Miles Stanford}

\section{References}

1. Multidisciplinary working group. Prenatal screening for toxoplasmosis in the UK. London: Royal College of Obstetricians and Gynaecologists, 1992.

2. Wilson CB, Remington JS, Stagro S, Reynolds DW. Development of adverse sequelae in children born with subclinical congenital toxoplasma infection. Paediatrics 1980;66:767-74.

3. Koppe JG, Rothova A. Congenital toxoplasmosis: a long term follow up of 20 years. Int Ophthalmol 1989;13:387-90.

4. Gilbert RE, Stanford MR, Jackson H, Holliman RE, Sanders MD. Incidence of acute symptomatic retinochoroiditis in South London according to country of birth. BMJ 1995;310:1037-40.

5. Glasner PD, Silveira C, Krusyan-Moran D, et al. An unusually high prevalence of ocular toxoplasmosis in Southern Brazil. Am J Ophthalmol 1992;114:136-44.

6. Piretti-Peyzi P, Accortini M, Tamburi S, Ciapparoni V, Abdulaziz MA. Clinical features of toxoplasmic retinochoroiditis in patients with acquired immunodeficiency syndrome. Am Ophthalmol 1994;26:73-84.

7. Holliman RE, Stevens PJ, Duffy KT, Johnson JD. Serological investigation of ocular toxoplasmosis. $\mathrm{Br} \mathrm{J}$ Opthalmol 1991;75:353-5.

8. Rothova A, Meenken C, Buitenhuis HJ, et al. Therapy for ocular toxoplasmosis. Am J Ophthalmol 1993;115:517-23.

9. Engstrom RE, Holland GN, Nussenblatt RB, Jabs DA. Current practices in the management of ocular toxoplasmosis. Am J Ophthalmol 1991;111:601-10.

10. Aranjo FG, Huskinson MJ, Gutteridge VE, Remington JS. In vitro and in vivo activities of the hydroxynaphthoquinone $566 \mathrm{C} 80$ against the cyst form of Toxoplasma gondii. Antimicrob Agents Chemother 1992;36:326-30. 